\title{
An outcome and cost analysis of anal fistula plug insertion $v s$ endorectal advancement flap for complex anal fistulae
}

\author{
O. M. Fisher*, D. A. Raptis*, D. Vetter*, A. Novak*, D. Dindo†, D. Hahnloserł, P.-A. Clavien* \\ and A. Nocito*§
}

*Department of Surgery, University Hospital Zurich, Zurich, Switzerland, †Department of Surgery, Triemli Hospital Zurich, Zurich, Switzerland, $\ddagger$ Department of Visceral Surgery, University Hospital Lausanne, Lausanne, Switzerland and §Department of Surgery, Cantonal Hospital Baden, Baden, Switzerland

Received 15 September 20।4; accepted 23 November 2014; Accepted Article online 31 December 2014

\section{Abstract}

Aim The study aimed to compare the rate of success and cost of anal fistula plug (AFP) insertion and endorectal advancement flap (ERAF) for anal fistula.

Method Patients receiving an AFP or ERAF for a complex single fistula tract, defined as involving more than a third of the longitudinal length of of the anal sphincter, were registered in a prospective database. A regression analysis was performed of factors predicting recurrence and contributing to cost.

Results Seventy-one patients (AFP 31, ERAF 40) were analysed. Twelve (39\%) recurrences occurred in the AFP and $17(43 \%)$ in the ERAF group $(P=1.00)$. The median length of stay was 1.23 and 2.0 days $(P<0.001)$, respectively, and the mean cost of treatment was $€ 5439 \pm € 2629$ and $€ 7957 \pm € 5905 \quad(P=0.021)$ respectively. On multivariable analysis, postoperative complications, underlying inflammatory bowel disease and fistula recurring after previous treatment were inde- pendent predictors of de novo recurrence. It also showed that length of hospital stay $\leq 1$ day to be the most significant independent contributor to lower cost $(P=0.023)$.

Conclusion Anal fistula plug and ERAF were equally effective in treating fistula-in-ano, but AFP has a mean cost saving of $€ 2518$ per procedure compared with ERAF. The higher cost for ERAF is due to a longer median length of stay.

Keywords Anal fistula, anal fistula plug, advancement mucosa flap, endorectal advancement flap, cost

\section{What does this paper add to the literature?}

The study demonstrates equal success for anal fistula plug (AFP) and endorectal advancement flap for anal fistula in a large series of patients treated in a specialist centre. Factors related to failure are defined. AFP offers a cost saving of more than $€ 2500$ per procedure.

\section{Introduction}

Anal fistula is common, with a reported incidence of 1.2-2.8 per $10000 /$ year [1]. It affects men more often than women in a ratio ranging from $2: 1$ to $5: 1[2,3]$. When the fistula track involves a large portion of the anal sphincter it is regarded as complex [4]. Although simple fistulotomy provides excellent healing rates, it

\footnotetext{
Correspondence to: Antonio Nocito, MD, Department of Surgery, Cantonal Hospital Baden, $\mathrm{CH}-5404$ Baden, Switzerland.

E-mail: antonio.nocito@ksb.ch

OMF and DAR contributed equally as first authors.

Trial Registration. ClinicalTrials.gov: NCTOI258I79

The data were presented at the Annual Swiss Surgical Society Meeting, June 2013
}

has a risk of some, usually minor, disturbance of continence variously reported to range from 6.7 to $52 \%$ $[5,6]$. For this reason treatments besides fistulotomy have been developed, including endorectal advancement flap (ERAF), insertion of an anal fistula plug (AFP), fibrin glue or ligation of the intersphincteric track (LIFT). Success rates of these procedures range from 30 to $50 \%[7]$.

Commonly performed procedures include insertion of an AFP or creation of an ERAF, often preceded by the initial insertion of a seton [8-13]. Following a consensus meeting on their indications and use [14], most reported success rates for AFPs have been around 50\% $[9,11,15,16]$. Reported success rates for ERAF have ranged from around $35 \%$ to nearly $100 \%$ [17]. None of these treatments has been shown to be superior over 
the others, largely through lack of comparative studies [8,18-20].

We undertook this prospective study of patients with a complex fistula track to compare AFP with ERAF including clinical success and cost.

\section{Method}

All patients were treated between 2007 and 2012 in the Department of Visceral and Transplantation Surgery of the University Hospital Zurich by three board-certified surgeons with European Board of Surgical Qualification (EBSQ) certification in coloproctology (DD, DH, AN). The diagnosis of anal fistula was made by rectal examination with or without anal ultrasound. In some cases pelvic magnetic resonance imaging (MRI) was performed. Only patients with one fistula track were included. Patients with rectovaginal, rectourinary or pouch-anal fistulae were excluded. A recurrent fistula was defined when some form of previous definitive treatment had been attempted, for example previous fistula surgery or seton insertion.

\section{Surgical procedure and follow-up}

The Surgisis $\AA^{\circledR}$ Anal Fistula PlugtM (Cook Medical Inc., Bloomington, Illinois, USA) was used in the unit from May 2007. Patients treated before this date had been treated by ERAF. Allocation of patients to each treatment group was at the treating surgeon's discretion. Following surgery all patients were seen at 2 weeks and then at regular intervals until healing or persistence of the fistula was judged to have occurred. Successful closure was defined as closure of the internal and external openings with no discharge. The time to failure was defined as the interval from operation to the point when physical examination confirmed persistence of the fistula.

\section{Anal fistula plug}

The patient underwent the procedure as an outpatient in the lithotomy position having had a single injection of cefuroxime $(1.5 \mathrm{~g})$ or ciprofloxacin $(0.2 \mathrm{~g})$ given intravenously with metronidazole $(0.5 \mathrm{~g})$. An intraoperative endoanal ultrasound was performed in all patients. Following curettage and cleansing of the track with hydrogen peroxide followed by saline solution $(0.9 \%)$, the AFP was inserted into the track via the internal opening. The tip of the plug was sutured at the internal opening with interrupted vicryl sutures and then covered with mucosa. The external part of the plug was trimmed to skin-level. Postoperatively, patients were instructed to shower the surgical site twice a day and after every defaecation. Stool softeners and regular analgesics were given as standard protocol. Postoperative antibiotic prophylaxis was administered to all patients until the first follow-up consultation.

\section{Endorectal advancement flap}

The operation was performed as an inpatient procedure and patients were discharged at a minimum of 24 h postsurgery with the decision to discharge the patient being made by one of the treating colorectal surgeons. Positioning and antibiotic administration was the same as for AFP treatment. Following proctoscopy and endosonography the external opening was circumcised and the track dissected to the internal opening. The internal opening was then circumcised and the entire track was removed. A flap consisting of mucosa, submucosa and some internal/circular muscle was raised and brought down over the site of the internal opening where it was fixed to the anal canal below this level by monocryl (4-0) sutures. The integrity of the suture line was checked by the injection of hydrogen peroxide solution. The remaining postoperative care was identical to AFP treatment.

\section{Data collection and management}

All patients were registered in a central, prospective database. Patient demographic data, comorbidity measured by the validated Charlson Comorbidity Index (CCI) [21], other relevant comorbidities not included in the CCI, information on intra-operative findings, procedures, type of surgery, postoperative care, postoperative complications and follow-up data were all recorded (Excel, Microsoft Office 2010; Microsoft Corporation, Redmond, Washington, USA).

\section{Calculation of cost}

Cost data were collected via the surgical department's accounting and billing services. All costs arising from the surgical procedures and hospital stay were included, but none of the cost of the preoperative consultation or outpatient follow-up were included. All patients' outof-pocket costs, travel and outpatient medication expenses were also excluded. The cost was adjusted for inflation and transformed from the nationally applied billing system TARMED (http://www.tarmedsuisse.ch/) into Swiss Francs (CHF) according to the current cantonal tariff structure if the patient was treated as an outpatient. The TARMED comprehensive billing system encodes medical activities according to their time requirement, complexity and use of infrastructure. The billing system differentiates between the doctor's activity and technical aspects such as the cost of the operation and wound care. Additionally, the 
Table I Patient demographics.

\begin{tabular}{lccccc}
\hline Characteristics & All patients $(n=71)$ & AFP $(n=31)$ & ERAF $(n=40)$ & OR $(95 \% \text { CI })^{*}$ & $P$-value \\
\hline Age (years), median (IQR) & $43(34-53)$ & $41(34-51)$ & $44(34-58)$ & - & 0.26 \\
Gender, male/female, $n(\%)$ & $47 / 24(66 / 34)$ & $17 / 14(55 / 45)$ & $29 / 11(73 / 27)$ & $0.46(0.17-1.24)$ & 0.14 \\
Charlson Comorbidity Index $>0, n(\%)$ & $7(10)$ & $6(19)$ & $1(3)$ & $0.10(0.01-0.91)$ & 0.04 \\
HIV (< CDC Stage C), $n(\%)$ & $2(3)$ & $1(3)$ & $1(3)$ & $1.38(0.08-22.97)$ & 1.00 \\
Diabetes (w/o sequelae), $n(\%)$ & $2(3)$ & $2(6)$ & - & - & 0.18 \\
IBD, $n$ (\%) & $11(16)$ & $9(29)$ & $2(5)$ & $7.77(1.54-39.26)$ & 0.008 \\
Smoking, $n(\%)$ & $21(30)$ & $11(36)$ & $10(25)$ & $1.80(0.64-5.02)$ & 0.30 \\
Recurrent fistulation, $n(\%)$ & $38(54)$ & $19(61)$ & $19(48)$ & $1.75(0.68-4.54)$ & 0.34 \\
Fistula recurrence, $n(\%)$ & $29(41)$ & $12(39)$ & $17(42)$ & $0.94(0.32-2.72)$ & 1.00 \\
\hline
\end{tabular}

*AFP indicates anal fistula plug; ERAF indicates endorectal advancement flap; OR \& 95\%CI indicate odds ratio and 95\% confidence interval; IQR indicates interquartile range; CDC indicates center for disease control; IBD indicates inflammatory bowel disease.

encoded tariff is not only adjusted to the treating physician's qualifications but also to the canton in which the treatment took place. The final bill a patient or paying third party (health insurance or similar) receives is therefore a summary of all these medical 'actions' encoded as tax points or numeric units, which are then transformed into the national currency using a cantonal formula (defined through cantonal contracts established through negotiations between the medical colleges, insurances and designated hospital representatives).

The cost of inpatient treatment is calculated according to the standardized accounting guidelines of the association of Swiss hospitals known as REKOLE® [22] using SAP (SAP, Business Warehouse, Walldorf, Germany). This analysis integrates complete in-hospital expenses including variable and fixed costs. The cost is directly attributed according to the services offered, on the treatment and bed accompanying areas. Using the exchange rate as provided by the Swiss bank UBS on 30 June 2014, displayed costs were converted to Euros $(€)$ at the following exchange rate: CHF $\mathrm{l}=€ 0.841$. The final bill is issued as would be sent to the thirdparty payer covering the cost of each treatment.

\section{Statistical analysis}

The primary end-points of the study were fistula healing and total treatment cost. Continuous variables were compared using the Mann-Whitney U-test or Student's $t$-test, where appropriate. Differences between proportions were compared using the Fisher exact or the Pearson $\chi^{2}$ test. All $P$-values were two-sided and considered statistically significant where $P \leq 0.05$. Stepwise backward logistic and linear regression analysis was performed for analysis of factors possibly relating to recurrence and cost [23]. Data are presented as mean $( \pm \mathrm{SD})$, median (interquartile range, IQR) and odds ratio (OR) with $95 \% \mathrm{CI}$ unless stated otherwise. All statistics were performed using spss Statistics Version 21 for Mac (spss: an IBM Company, Chicago, Illinois, USA) and R Statistical Packages with the use of the GGPLOT2 package [24,25].

\section{Results}

\section{Patient demographics and fistula characteristics}

Seventy-one patients were entered into the study. Thirty-one received an AFP (44\%) and 40 (56\%) an ERAF. Patient demographic data and comorbidity are summarized in Table 1 and fistula characteristics in Table 2. Eleven patients had inflammatory bowel disease [IBD; Crohn's disease (CD) $n=10$; ulcerative colitis (UC) $n=1]$, nine in the AFP and two in the ERAF group. There were significantly more patients with IBD in the AFP group $(29.0 \%$ vs $5.0 \%$;

Table 2 Fistula characteristics.

\begin{tabular}{lcccc}
\hline Fistula type & All patients $(n=71)$ & AFP $(n=31)$ & ERAF $(n=40)$ & $P$-value \\
\hline Transphincteric, $n(\%)$ & $51(72)$ & $23(74)$ & $28(70)$ & 0.79 \\
Intersphincteric, $n(\%)$ & $10(14)$ & $2(3)$ & $8(20)$ & 0.17 \\
Suprasphincteric, $n(\%)$ & $3(4)$ & $3(4)$ & $0(0)$ & 0.03 \\
Extrasphincteric, $n(\%)$ & $5(7)$ & $2(6)$ & $1(3)$ & 1.00 \\
Combined, $n(\%)$ & $2(3)$ & $1(3)$ & & 1.00 \\
\hline
\end{tabular}


Table 3 Postoperative complications.

\begin{tabular}{lccccc}
\hline Complication type & All patients $(n=71)$ & AFP $(n=31)$ & ERAF $(n=40)$ & OR $(95 \% \text { CI })^{*}$ & $P$-value \\
\hline SSI, $n(\%)$ & $6(9)$ & $2(7)$ & $4(10)$ & $0.25(0.03-2.25)$ & 0.39 \\
Abscess, $n(\%)$ & $10(14)$ & $4(13)$ & $6(15)$ & $0.90(0.23-3.51)$ & 1.00 \\
SSI or abscess, $n(\%)$ & $16(23)$ & $5(16)$ & $11(28)$ & $0.51(0.16-1.65)$ & 0.39 \\
Persistent sinus, $n(\%)$ & $1(1)$ & - & $1(3)$ & - & 1.00 \\
Haematoma, $n(\%)$ & $1(1)$ & - & - & - & 1.00 \\
Plug loss or protrusion, $n(\%)$ & $2(3)$ & $2(7)$ & - & - & 0.18 \\
Other, $n(\%)$ & $1(1)$ & $1(3)$ & $12(30)$ & $0.96(0.34-2.67)$ & 1.00 \\
Total, $n(\%)$ & $21(30)$ & $9(29)$ & & - & -42 \\
\hline
\end{tabular}

*AFP indicates anal fistula plug; ERAF indicates endorectal advancement flap; OR \& 95\%CI indicate odds ratio and 95\% confidence interval; IQR indicates interquartile range; SSI indicates surgical site infection.

$P=0.008)$. Six patients with $\mathrm{CD}$ were on biological therapy (one patient on simultaneous steroid therapy) and three were on no treatment at the time of surgery.
None of the patients with IBD in the ERAF group were receiving treatment. Recurrent fistulation was present in 19 patients receiving ERAF (48\%) and 19 having AFP

Table 4 Uni- and multivariable analysis for de novo recurrence.

\begin{tabular}{|c|c|c|c|c|c|c|}
\hline \multirow[b]{2}{*}{ Factors } & \multirow[b]{2}{*}{ All $(n=71)$} & \multirow[b]{2}{*}{ Recurrence $(n=29)$} & \multicolumn{2}{|l|}{ Univariable analysis } & \multicolumn{2}{|l|}{ Multivariable analysis } \\
\hline & & & OR $(95 \% \mathrm{CI})^{*}$ & $P$-value & OR $(95 \% \mathrm{CI})^{*}$ & $P$-value \\
\hline \multicolumn{7}{|l|}{ Age (years), $n(\%)$} \\
\hline$\geq 40$ & $41(58)$ & $18(62)$ & $0.74(0.28-1.94)$ & 0.63 & $1.82(0.53-6.22)$ & 0.34 \\
\hline$<40$ & $30(42)$ & $11(38)$ & - & - & - & - \\
\hline \multicolumn{7}{|l|}{ Gender, $n(\%)$} \\
\hline Male & $46(65)$ & $19(66)$ & $1.06(0.39-2.85)$ & 1.00 & $1.06(0.27-4.15)$ & 0.95 \\
\hline Female & $25(35)$ & $10(34)$ & - & - & - & - \\
\hline \multicolumn{7}{|l|}{ Therapeutic group, $n(\%)$} \\
\hline Anal fistula plug & $31(44)$ & $12(41)$ & $0.85(0.33-2.22)$ & 0.81 & $1.09(0.09-3.94)$ & 0.90 \\
\hline Endorectal advancement flap & $40(56)$ & $17(59)$ & - & - & - & - \\
\hline \multicolumn{7}{|l|}{ Smoking status, $n(\%)$} \\
\hline Smoker & $21(30)$ & $17(59)$ & $2.59(0.91-7.35)$ & 0.11 & $2.67(0.80-8.84)$ & 0.11 \\
\hline Nonsmoker & $50(70)$ & $12(41)$ & - & - & - & - \\
\hline \multicolumn{7}{|c|}{ Charlson Comorbidity Index, $n(\%)$} \\
\hline$>0$ & $7(10.0)$ & $3(10)$ & $0.88(0.18-4.26)$ & 1.00 & $1.48(0.75-2.94)$ & 0.26 \\
\hline$=0$ & $63(90)$ & $25(90)$ & - & - & - & - \\
\hline \multicolumn{7}{|c|}{ Inflammatory bowel disease, $n(\%)$} \\
\hline Yes & $11(15)$ & $2(7)$ & $0.27(0.05-1.37)$ & 0.18 & $4.30(0.75-24.57)$ & 0.10 \\
\hline No & $60(85)$ & $27(93)$ & - & - & - & - \\
\hline \multicolumn{7}{|l|}{ Recurrent fistulation, $n(\%)$} \\
\hline Yes & $39(55)$ & $21(72)$ & $3.50(1.26-9.69)$ & 0.02 & $4.03(1.33-12.20)$ & 0.01 \\
\hline No & $32(45)$ & $8(28)$ & - & - & - & - \\
\hline \multicolumn{7}{|l|}{ Previous fistula surgery, $n(\%)$} \\
\hline Yes & $38(54)$ & $19(66)$ & $2.30(0.87-6.11)$ & 0.15 & $1.75(0.35-6.80)$ & 0.58 \\
\hline No & $33(46)$ & $10(34)$ & - & - & - & - \\
\hline \multicolumn{7}{|c|}{ Postoperative antibiotics, $n(\%)$} \\
\hline Yes & $66(93)$ & $26(90)$ & $0.43(0.07-2.77)$ & 0.39 & $2.99(0.25-35.63)$ & 0.39 \\
\hline No & $5(7)$ & $3(10)$ & - & - & - & - \\
\hline \multicolumn{7}{|c|}{ Postoperative complication, $n(\%)$} \\
\hline Yes & $21(30)$ & $12(41)$ & $2.59(0.91-7.35)$ & 0.11 & $4.00(1.94-10.52)$ & 0.04 \\
\hline No & $50(70)$ & $17(59)$ & - & - & - & - \\
\hline
\end{tabular}

* OR \& 95\%CI indicate odds ratio and 95\% confidence interval. 


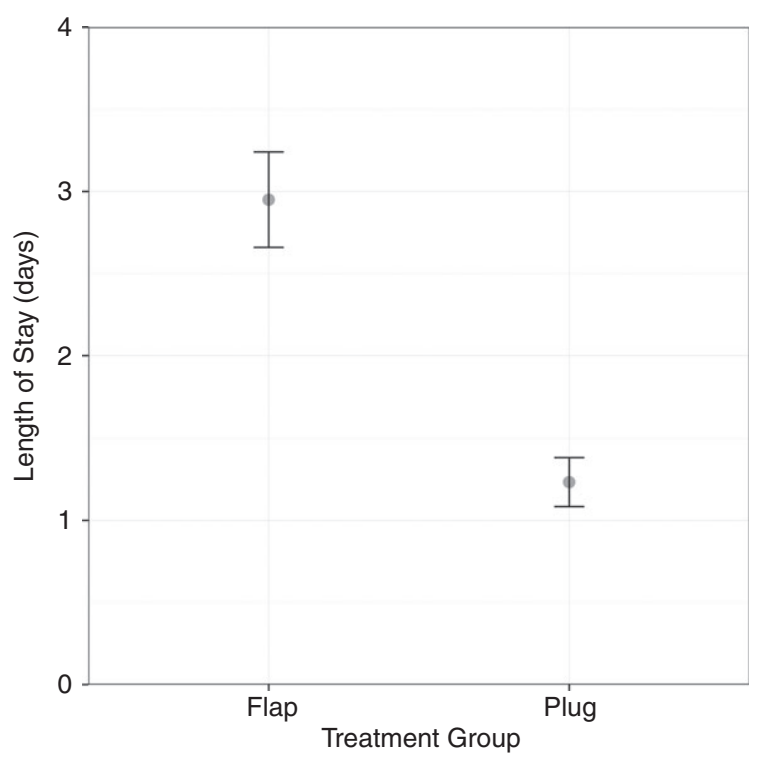

Figure I Median length of stay of patients treated with an endorectal advancement flap ('Flap'; 2.0 days) $v s$ anal fistula plug ('Plug'; 1.23 days; $P<0.001$ ).

(61\%; $P=0.338)$. Ten patients having ERAF $(25 \%)$ and $11(36 \%)$ having AFP were smokers at the time of surgery $(P=0.30)$. Patients with a recurrent fistula were more likely to be smokers than non-smokers (OR $3.76,95 \%$ CI $1.19-11.84, P=0.035)$. There was no difference in the use of preoperative imaging modalities between the groups (data not shown).

\section{Recurrence}

Twelve (39\%) patients having AFP and 17 (43\%) patients having ERAF developed de novo recurrence of the fistula (OR 0.94, 95\% CI 0.32-2.72, $P=1.00$ ). The median time to recurrence was 3.0 months (range 2.0 for ERAF and 4.8 for AFP) for both treatment groups. Forty-three $(61 \%)$ of the 72 patients had had a previous seton placement, including $24(77 \%)$ in the AFP and $19(48 \%)$ in the ERAF group (OR 3.79, 95\% CI $1.33-10.79, P=0.014)$. There was no difference in the proportion of patients taking antibiotics postoperatively $(97 \%$ vs $90 \%, P=0.39)$, although the median duration of treatment was longer in the AFP group (16 vs 12 days, $P=0.004)$.

\section{Postoperative complications}

Postoperative complications were defined as 'any deviation from the ideal postoperative course that is not inherent in the procedure and does not comprise a failure to cure' [26]. Twelve patients (30\%) in the ERAF group had a postoperative complication (Table 3 ), one of whom required reoperation for a haematoma. Apart from another patient who developed a persistent postoperative sinus with no obvious connection with the anal canal, the remaining 10 patients all received successful antibiotic treatment for local infection of the wound.

Nine $(29 \%)$ patients developed a postoperative complication after AFP insertion. Four developed an abscess or purulent infection of the track without abscess formation. One patient had lost the plug by the time of the first follow-up and another plug extrusion was treated conservatively. One patient developed severe constipation requiring laxatives. One patient developed early failure and sought treatment elsewhere. There was no difference in the frequency of complications between the two groups (OR 0.96, 95\% CI 0.34-2.67, $P=1.00)$.

\section{Length of stay and follow-up}

The median length of stay was 2 (IQR 1-3) days and was significantly less after AFP [1.23 (IQR 1-1) vs 2.0 (IQR 2-3) days, $P<0.001$; Fig. 1]. The median duration of follow-up for all patients was 6 (IQR 2-12) months $[8$ (IQR 3.3-12.8) vs 4 (IQR 2.2-7.3), $P=0.30]$. At this point $12(39 \%)$ patients receiving AFP developed recurrence compared with 17 (43\%) after ERAF $(P=1.00)$. Only two of the patients who developed recurrence had IBD. The median time to the diagnosis of recurrence was 4 (IQR 1.5-7.5) months and 3 (IQR 2.0-4.0) months $(P=0.66)$, respectively. Of the patients who had an infectious complication, $56 \%$ developed recurrence, which was independent of the treatment group (AFP 2, ERAF 7, $P=0.23$ ).

On multivariable analysis the occurrence of any type of postoperative complication (OR 4.0, 95\% CI 1.94 10.52, $P=0.04$ ) and recurrent fistulation (OR 4.03, 95\% CI 1.3-12.2, $P=0.01)$ were independent contributing factors for de novo recurrence. Underlying IBD was not an independent predictor for recurrence (OR 4.3, 95\% CI 0.7-24.6, $P=0.10$; Table 4).

\section{Cost}

The mean treatment cost in the two groups was $€ 5439$ $( \pm € 2629)$ for AFP and $€ 7957$ ( $\pm € 5905)$ for ERAF $(P=0.021)$ (Fig. 2). Hospital length of stay was positively correlated with cost (Spearman's correlation coefficient $0.456,95 \%$ CI $0.22-0.65, P<0.001)$. On univariable analysis, AFP treatment and length of hospital stay $<1$ day were associated with a lower cost. In a multivariable regression model including age, gender, 
Table 5 Uni- and multivariable analysis of cost.

\begin{tabular}{|c|c|c|c|c|}
\hline \multirow[b]{2}{*}{ Factors } & \multicolumn{2}{|l|}{ Univariable analysis } & \multicolumn{2}{|l|}{ Multivariable analysis } \\
\hline & Mean $\left(\mathrm{SD}^{*}\right)$, Euros & $P$-value & Costs $\Delta(95 \% \mathrm{CI})^{*}$ & $P$-value \\
\hline \multicolumn{5}{|l|}{ Age in years } \\
\hline$\geq 40$ & $7396(6041)$ & 0.99 & $-681(-3282$ to 1926$)$ & 0.60 \\
\hline$<40$ & $6271(3045)$ & - & - & - \\
\hline \multicolumn{5}{|l|}{ Gender } \\
\hline Male & $7346(5944)$ & 0.53 & $213(-2606$ to 3032$)$ & 0.88 \\
\hline Female & $6117(2261)$ & - & - & - \\
\hline \multicolumn{5}{|l|}{ Therapeutic group } \\
\hline Anal fistula plug & $5439(2672)$ & 0.04 & $-1462(-6293$ to 3369$)$ & 0.55 \\
\hline Endorectal advancement flap & $7957(5979)$ & - & - & - \\
\hline \multicolumn{5}{|l|}{ Smoking status } \\
\hline Smoker & $6239(3103)$ & 0.71 & $-839(-3654$ to 1975$)$ & 0.53 \\
\hline Nonsmoker & $7220(5646)$ & - & - & - \\
\hline \multicolumn{5}{|l|}{ Charlson Comorbidity Index } \\
\hline$>0$ & $7991(5957)$ & 0.65 & $-2656(-6731$ to 1418$)$ & 0.20 \\
\hline$=0$ & $6189(5022)$ & - & - & - \\
\hline \multicolumn{5}{|l|}{ Inflammatory bowel disease } \\
\hline Yes & $5711(3149)$ & 0.74 & $30(-4143$ to 4211$)$ & 0.99 \\
\hline No & $7133(5281)$ & - & - & - \\
\hline \multicolumn{5}{|l|}{ Recurrent fistula } \\
\hline Yes & $7475(6393)$ & 0.55 & $1412(-1004$ to 4318$)$ & 0.17 \\
\hline No & $6324(2781)$ & - & - & - \\
\hline \multicolumn{5}{|l|}{ Previous fistula surgery } \\
\hline Yes & $7078(6230)$ & 0.71 & $397(-3196$ to 3990$)$ & 0.83 \\
\hline No & $7084(5318)$ & - & - & - \\
\hline \multicolumn{5}{|l|}{ Postoperative complications } \\
\hline Yes & $7084(5318)$ & 0.74 & $-326(-3069$ to 2415$)$ & 0.81 \\
\hline No & $6607(4474)$ & - & - & - \\
\hline \multicolumn{5}{|l|}{ Length of stay } \\
\hline$\leq 1$ day & $5028(2547)$ & 0.01 & $-3000(-5570$ to -431$)$ & 0.023 \\
\hline$>1$ day & $7943(5733)$ & - & - & - \\
\hline
\end{tabular}

* $\mathrm{SD}$ indicates standard deviation; $95 \% \mathrm{CI}$ indicates $95 \%$ confidence interval.

therapeutic group (AFP vs ERAF), smoking status, CCI, IBD, recurrent fistula, previous fistula surgery, postoperative complications and length of stay, a length of hospital stay of $<1$ day was independently associated with lower cost (cost $\Delta-€ 3000,95 \%$ CI $-€ 5570$ to $-€ 431, P=0.023)$. Table 5 provides an overview of the effect the aforementioned variables had on overall treatment costs.

\section{Discussion}

This retrospective analysis of a prospectively maintained database has shown no difference in the failure rate of the AFP and ERAF procedures. The latter was more expensive, largely due to the extra time required in hospital.

The groups were not balanced, for example the number of patients with IBD was significantly higher in the AFP group (ERAF was not generally selected for such patients owing to the high failure rates of this procedure reported in the literature [17,27-29]). Further, the number of patients with comorbidities other than IBD was also significantly higher in the AFP group compared with those receiving ERAF. These differences in comorbidities, especially IBD, should have favoured ERAF. It may therefore be significant that there was no difference in success between the groups. The recurrence rate of approximately $40 \%$ in both groups is of the same order as reported in the literature $[9,11,15,16]$, in accordance with a recent meta-analysis of AFP and ERAF which found no difference in recurrence between them [8].

The low recurrence rate in the AFP group may in part be due to fewer plug losses (6\%) compared with the literature $(10-20 \%)[8,19,20]$. Additionally the low rate of surgical site infection or abscess formation com- 


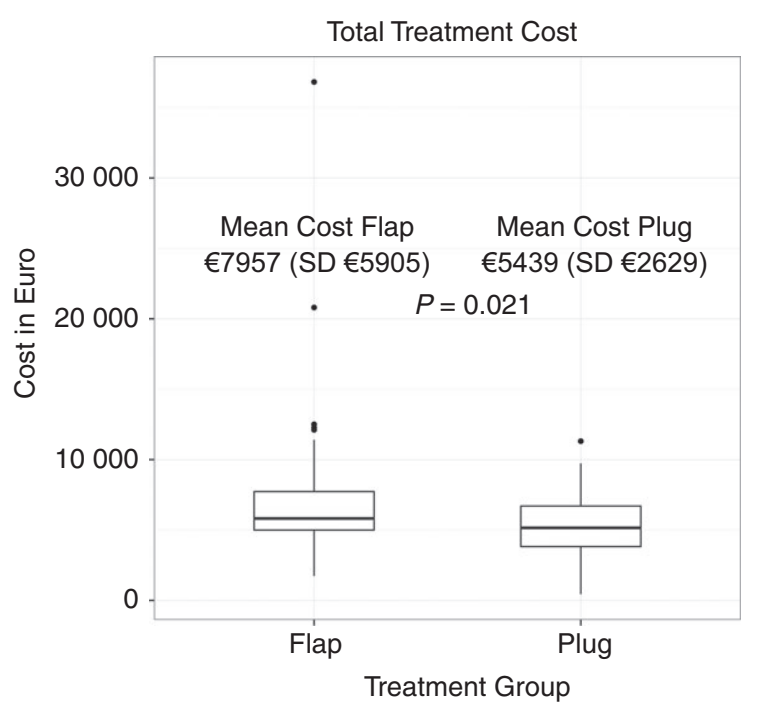

Figure 2 Comparison of overall treatment cost by treatment group. As shown, overall treatment cost for patients receiving endorectal advancement flap (Flap) was significantly higher than those patients receiving anal fistula plug (Plug).

pared with other studies (19\% vs 30\%) [10,16] could be another explanation. With only three certified colorectal surgeons performing the plug insertions a high level of expertise was guaranteed, and this may also have positively influenced the recurrence rate. A limitation of the study is that the length of the fistula track was not measured. This is related to success of treatment, especially with AFP [30]. It is unknown whether or not selection bias of patients with longer fistula tracts applied to the study.

A further limitation is the short duration of followup (6 months), even though it is comparable to other published series [31]. So far no late contact has been made by any patient since the date of entry of the last patients in 2012, although it is conceded that the follow-up was much longer (12-15 months) in patients who did have a recurrence than in those who did not (5-8 months).

Healing was reduced by any type of postoperative complication. Interestingly, there is a lack of data on infectious complications in the literature, but in line with our findings postoperative infection rates of about $30 \%$ have been reported for AFP $[10,16]$. In contrast, the only study explicitly commenting on this aspect, found no postoperative septic complications after ERAF [32].

Anal fistula plug was the cheaper of the two procedures due to the shorter patient stay. This finding is in agreement with the only study, including 24 patients, to have assessed the cost of AFP and ERAF [31]. In line with our data, the authors found no difference in recurrence and found the plug to be more cost-effective, with a median saving of $\$ 1588(\sim 1247)$ and 1.5 hospital days.

The above study [31] was performed in Canada, which has lower total health costs than Switzerland [33], but even taking this into account, AFP is cheaper. This was also seen in our study in the cost of medical and nursing services, which were persistently higher in ERAF than AFP. There are several reports on hospital stay of ERAF, most of which are of the order of a at least 1 to a few days.

In conclusion, the present study, found that the results of AFP were not significantly different from those of ERAF despite a considerably lower cost. This is largely due to the in-hospital stay occasioned by the latter procedure. Failure was common after either procedure.

\section{Author contributions}

OMF: study conception and design, data collection and analysis, writing and editing of the manuscript following review by co-authors. DAR: study conception and design, data analysis, writing and editing of the manuscript. DV: data analysis, editing of the manuscript. AN and DD: patient identification and treatment, critical manuscript review. DH: patient identification and treatment, editing of the manuscript and critical review. PAC: acquisition of institutional funding, critical manuscript review. AN: study conception, design and supervision, patient identification and treatment, manuscript editing and review.

\section{Conflict of interest}

The authors have no conflict of interest.

\section{References}

l Zanotti C, Martinez-Puente C, Pascual I, Pascual M, Herreros D, Garcia-Olmo D. An assessment of the incidence of fistula-in-ano in four countries of the European Union. Int J Colorectal Dis 2007; 22: 1459-62.

2 Oliver I, Lacueva FJ, Perez Vicente F et al. Randomized clinical trial comparing simple drainage of anorectal abscess with and without fistula track treatment. Int $J$ Colorectal Dis 2003; 18: 107-10.

3 Vasilevsky CA, Gordon PH. The incidence of recurrent abscesses or fistula-in-ano following anorectal suppuration. Dis Colon Rectum 1984; 27: 126-30.

4 Marks CG, Ritchie JK. Anal fistulas at St Mark's Hospital. Br J Surg 1977; 64: 84-91.

5 van Tets WF, Kuijpers HC. Continence disorders after anal fistulotomy. Dis Colon Rectum 1994; 37: 1194-7. 
6 Garcia-Aguilar J, Belmonte C, Wong DW, Goldberg SM, Madoff RD. Cutting seton versus two-stage seton fistulotomy in the surgical management of high anal fistula. $\mathrm{Br} J$ Surg 1998; 85: 243-5.

7 Dudukgian $\mathrm{H}$, Abcarian $\mathrm{H}$. Why do we have so much trouble treating anal fistula? World J Gastroenterol 2011 ; 17: 3292-6.

8 Leng Q, Jin HY. Anal fistula plug vs mucosa advancement flap in complex fistula-in-ano: a meta-analysis. World J Gastrointest Surg 2012; 4: 256-61.

9 Christoforidis D, Etzioni DA, Goldberg SM, Madoff RD, Mellgren A. Treatment of complex anal fistulas with the collagen fistula plug. Dis Colon Rectum 2008; 51: $1482-7$.

10 Lawes DA, Efron JE, Abbas M, Heppell J, Young-Fadok TM. Early experience with the bioabsorbable anal fistula plug. World J Surg 2008; 32: 1157-9.

11 Schwandner O, Stadler F, Dietl O, Wirsching RP, Fuerst A. Initial experience on efficacy in closure of cryptoglandular and Crohn's transsphincteric fistulas by the use of the anal fistula plug. Int J Colorectal Dis 2008; 23: 319-24.

12 Garg P. To determine the efficacy of anal fistula plug in the treatment of high fistula-in-ano: an initial experience. Colorectal Dis 2009; 11: 588-91.

13 Thekkinkattil DK, Botterill I, Ambrose NS et al. Efficacy of the anal fistula plug in complex anorectal fistulae. Colorectal Dis 2009; 11: 584-7.

14 The Surgisis AFP anal fistula plug: report of a consensus conference. Colorectal Dis 2008; 10: 17-20.

15 van Koperen PJ, D'Hoore A, Wolthuis AM, Bemelman WA, Slors JF. Anal fistula plug for closure of difficult anorectal fistula: a prospective study. Dis Colon Rectum 2007; 50: $2168-72$.

16 Ky AJ, Sylla P, Steinhagen R, Steinhagen E, Khaitov S, Ly EK. Collagen fistula plug for the treatment of anal fistulas. Dis Colon Rectum 2008; 51: 838-43.

17 Soltani A, Kaiser AM. Endorectal advancement flap for cryptoglandular or Crohn's fistula-in-ano. Dis Colon Rectum 2010; 53: 486-95.

18 Christoforidis D, Pieh MC, Madoff RD, Mellgren AF. Treatment of transsphincteric anal fistulas by endorectal advancement flap or collagen fistula plug: a comparative study. Dis Colon Rectum 2009; 52: 18-22.

19 Ortiz H, Marzo J, Ciga MA, Oteiza F, Armendariz P, de Miguel M. Randomized clinical trial of anal fistula plug ver- sus endorectal advancement flap for the treatment of high cryptoglandular fistula in ano. Br J Surg 2009; 96: 608-12.

20 van Koperen PJ, Bemelman WA, Gerhards MF et al. The anal fistula plug treatment compared with the mucosal advancement flap for cryptoglandular high transsphincteric perianal fistula: a double-blinded multicenter randomized trial. Dis Colon Rectum 2011; 54: 387-93.

21 Charlson M, Szatrowski TP, Peterson J, Gold J. Validation of a combined comorbidity index. J Clin Epidemiol 1994; 47: $1245-51$.

22 Besson P. Cost Object Accounting (Die Kostenträgerrechnung). Bern: Stämpfli Publikationen, 2008.

23 Lemeshow DWHaS. Applied Logistic Regression. 2nd edition. New York: John Wiley and Sons, 2000

24 Wickham H. Ggplot2: Elegant Graphics for Data Analysis. New York: Springer, 2009. viii, 212 p.

25 Team RC. R: A Langange and Environment for Statistical Computing. R Foundation for Statistical Computing, 2013. http://www.R-project.org.

26 Dindo D, Clavien PA. What is a surgical complication? World J Surg 2008; 32: 939-41.

27 Marks CG, Ritchie JK, Lockhart-Mummery HE. Anal fistulas in Crohn's disease. Br J Surg 1981; 68: 525-7.

28 Chung W, Ko D, Sun C, Raval MJ, Brown CJ, Phang PT. Outcomes of anal fistula surgery in patients with inflammatory bowel disease. Am J Surg 2010; 199: 609-13.

29 O'Riordan JM, Datta I, Johnston C, Baxter NN. A systematic review of the anal fistula plug for patients with Crohn's and non-Crohn's related fistula-in-ano. Dis Colon Rectum 2012; 55: 351-8.

30 McGee MF, Champagne BJ, Stulberg JJ, Reynolds H, Marderstein E, Delaney CP. Tract length predicts successful closure with anal fistula plug in cryptoglandular fistulas. Dis Colon Rectum 2010; 53: 1116-20.

31 Adamina M, Hoch JS, Burnstein MJ. To plug or not to plug: a cost-effectiveness analysis for complex anal fistula. Surgery 2010; 147: 72-8.

32 Perez F, Arroyo A, Serrano P et al. Randomized clinical and manometric study of advancement flap versus fistulotomy with sphincter reconstruction in the management of complex fistula-in-ano. Am J Surg 2006; 192: 34-40.

33 OECD. OECD Health Statistics, 2013. http://www.compareyourcountry.org/health?cr=oecd\&crl=oecd\&lg=en\&page $=2($ accessed 22 October 2014). 